\title{
The influence of macroeconomic factors on personal income distribution in developing countries: A parametric modelling approach
}

\author{
C. García ${ }^{\mathrm{a}}$, M. Prieto-Alaiz ${ }^{\mathrm{b}}$ and H. Simón ${ }^{\mathrm{c}, *}$ \\ ${ }^{a}$ Universidad de Alcalá, Alcalá de Henares, Spain \\ ${ }^{\mathrm{b}}$ Universidad de Valladolid, Valladolid, Spain \\ ${ }^{\mathrm{c}}$ Universidad de Alicante-IEI-IEB, Alicante, Spain
}

\begin{abstract}
This article examines the influence of macroeconomic factors on personal income distribution in developing countries using a parametric modelling approach. The technique is based on the selection and estimation of a theoretical parametric model (a Dagum distribution) which fits accurately to the empirical income distributions of the countries examined. The parameters of the model specifically related to inequality are subsequently used as dependent variables in econometric models in order to examine the impact that certain macroeconomic variables (GDP growth, inflation, employment and real interest rates) have on inequality. The results reveal that GDP growth, employment rate and real interest rate are the macroeconomic factors with greater impact in shaping personal income distribution in developing countries.
\end{abstract}

\footnotetext{
* Corresponding autor. E-mail: h.simon@ua.es
}

This study benefits from funding support of the projects CSO2011-29943-C03-02 of the Ministerio de Educación, Cultura y Deporte and ECO2012-32178 of the Ministerio de Economía y Competitividad of Spain. We would like to thank Maria Dolores de Prada for her comments on an earlier version. 


\section{Introduction}

The analysis of the impact that macroeconomic factors such as unemployment, inflation, growth and other variables have on personal income distribution is an area that has received much attention in economic literature (i.e. Kuznets, 1955; Bourguignon, 2003; Chen and Ravallion, 2010). The purpose of this article is to contribute to this literature by examining the influence of macroeconomic factors on income distributions in the context of developing countries using a parametric modelling approach. This methodology facilitates an in-depth analysis of the simultaneous influence of macroeconomic variables on personal income distribution.

The methodology of the earliest studies in this line of research was a regressionbased approach based on estimating econometric models whose dependent variables were specific inequality measures or the proportion of total income received by certain quantiles of the total population and whose independent variables were macroeconomic factors ${ }^{2}$. Yet, the use of a particular inequality index may limit the scope of the analysis as it measures a particular type of inequality and, consequently, the evidence obtained may depend on the particular index used. Similarly, the examination of income distribution based on the income share of a particular quantile is also incomplete because it focuses on a specific part of the population.

Seeking to overcome these deficiencies, Jäntti and Jenkins (2010) used in a recent contribution a new methodology based on parametric modelling approach for examining the effect of macroeconomic variables on income distribution using longitudinal data for the UK, refining the seminal studies regarding parametric models and macroeconomic factors of Thurow (1970) and Salem and Mount (1974). Their methodology comprises two

\footnotetext{
${ }^{2}$ A review of these studies can be found in Parker (1999).
} 
stages. The first stage is concerned with the parametric modelling of the empirical personal income distribution on the basis of a theoretical functional form that provides a good fit to income data so that the characteristics of the distribution can be summarised in a small number of parameters. The second stage consists of econometric estimations of a multivariate linear regression model whose dependent variables are the estimated parameters of the theoretical distribution and whose regressors are macroeconomic factors. This approach provides a more complete perspective of the distributive impacts of macroeconomic determinants in inequality than that obtained by using a specific inequality index, given that the effects of macroeconomic indicators on a full set of distributional measures (including income mean, median, quantiles, income shares, distribution tails and several inequality and poverty indices) can be examined because all this measures can be expressed as functions of the estimated parameters.

This article applies these new developments to the analysis of the determinants of income distribution in developing countries, a field where the evidence on the impact of the macroeconomic factors on inequality is rather scarce and inconclusive. Although we use a parametric modelling approach, a major difference with the methodology used by Jäntti and Jenkins (2010) is that the parameters of a Dagum model are employed here in order to examine the determinants of inequality of a cross-section of countries, whereas Jäntti and Jenkins (2010) used the Singh-Maddala model from a time series perspective for a single country. The choice of the Dagum distribution is based on the fact that, among other attractive properties (García and Prieto, 2011), it is more flexible around the origin, the region where there is a larger proportion of data, and, therefore, could favour a better fit to the empirical distributions than the Singh-Maddala distribution (Kleiber, 1996). We also obtain a different variance and covariance matrix of joint errors of the multivariate 
linear regression model estimated in the second phase of econometric analysis. By adopting this new approach it is observed that growth, employment rates and real interest rates are the macroeconomic factors with greater impact on personal income distribution in developing countries.

The article is organised as follows. After the introduction, the second section reviews previous studies addressing the distributive effects of macroeconomic factors. The third section defines the methodology, comprising the most relevant aspects of the parametric modelling of personal income distributions and the estimation of econometric models in order to measure the impact of macroeconomic factors. The data on income distribution and macroeconomic indicators are described in the fourth section. The results obtained are presented in the fifth section. Finally, the main conclusions are expounded in the final section.

\section{Literature review}

One of the pioneer studies on the relationship between macroeconomic factors and inequality is Kuznets (1955). According to Kuznets' hypothesis there is an inverted Ushaped relation between economic inequality and economic growth. Kuznets claimed that inequality increases during the early stages of economic development, when an economy experiences a structural shift away from agriculture towards industry. Subsequently, inequality falls as the workforce in the industrial sector grows and it diminishes in the agricultural sector. Yet, empirically, the relationship between growth and inequality is highly ambiguous. Consequently, a number of studies do not find a systematic relationship between income distribution and growth (i.e. Deininger and Squire, 1996; Fields, 1989; 
Thornton, 2001), although this lack of empirical relationship could be explained by measurement errors in data sources (Ravallion, 2003) ${ }^{3}$.

Another basic macroeconomic factor on which studies on inequality have focused is inflation. The effects of inflation on income distribution could work in opposite directions. If inflation rises, individuals may prefer to invest in financial instruments which offer a higher profitability than keeping liquid assets. Therefore, individuals with lower income levels should be most affected by the effect of inflation, as they have a lower investment capacity. However, inflation can also have a positive effect for individuals with scarce resources, given that in general they are also those more indebted and an increase in inflation tends to diminish the relative debt level. As in the case of the growth rate, the empirical evidence on the effect of inflation on inequality is rather mixed. Thus, whereas some studies find that the influence of inflation on inequality is not significant (Blinder and Esaki, 1978; Cutler and Katz, 1991), others observe that higher inequality is apparently associated with higher inflation (see, e.g. Bulìr, 2001; Al-Marhubi, 2000).

Regarding the influence of unemployment on income distribution, given that those individuals most affected by unemployment tend to be located in the middle and lower parts of the distribution, rising unemployment is expected to be associated with a higher income inequality. The empirical evidence regarding the effect of unemployment levels on inequality is actually rather conclusive. Thus, Blank and Blinder (1986), Cutler and Katz (1991) and Castañeda, Díaz-Giménez and Ríos-Rull (1998) find that unemployment has a statistically significant negative effect on the total income share of the poorer population in the United States.

\footnotetext{
${ }^{3}$ On the contrary, there is less ambiguity in the relationship between growth and poverty, an area where a large number of studies have been conducted (for a review, see Chen and Ravallion, 2010).
} 
Finally, the relationship between inequality and interest rates is theoretically more complex because of the different effects of interest rates on credit markets depending on the level of development and the transmission mechanisms of monetary policy in each country (see, for example, Aghion and Bolton, 1997 and Piketty, 1997). Empirically, the evidence on the impact of interest rates on inequality is rather mixed. Thus, whereas Milanovic (2005) finds that an increase in real interest rates gives rise to mechanisms that increase inequality in developing countries, Jäntti and Jenkins (2010) show that the real interest rate is not a significant determinant of the evolution of inequality for the UK.

\section{Methodology}

In this section, the methodology used in order to analyse how macroeconomic factors influence personal income distribution is presented. This methodology is based, firstly, on the parametric modelling of personal income distribution and, secondly, on the use of the estimated parameters to study the distributive consequences derived from the variation in particular macroeconomic variables. The most relevant aspects of each of these stages are described below.

\section{Parametric modelling of personal income distribution}

The first phase of the methodology consists of fitting a parametric model to the empirical distribution of income data. This parametric approach assumes that income distribution can be represented by a member of the group of perfectly-specified continuous distribution functions, except for a vector of unknown parameters. One member of this group, the three-parameter Dagum distribution (Dagum, 1977), was selected due to its highly attractive properties. On the one hand, it is invertible and, therefore, it has a closedform expression for its distribution function (Kleiber, 1996), which is useful to obtain 
analytic expressions of some distributional statistics such as the quantile function and to easily conduct simulation. In addition, it has been empirically proved that with a lower number of parameters it provides a fit as good as tetraparametric distributions (McDonald, 1984). Finally, the Dagum model is more flexible in the part of the distribution where there are a greater number of observations, the region around the origin, and could provide a better fit than other three-parameter distributions such as the Singh-Maddala distribution (Kleiber, 1996). Some examples of this better performance of the Dagum model may be found in McDonald and Xu (1995) and Victoria-Feser (1995 and 2000).

The Dagum distribution has the following functional form:

$$
F_{\theta}(x)=D(x ; a, b, p)=\left(1+\left(\frac{x}{b}\right)^{-a}\right)^{-p} \quad x>0, a, b, p>0
$$

where $b$ is a scale parameter and $a$ and $p$ are inequality parameters.

Focusing on the influence and the economic interpretation of the parameters related to inequality ${ }^{4}$, parameter $a$ is inversely related to the level of inequality and poverty and it affects mainly the right tail of income distribution. In particular, an increase in this parameter implies a transfer of income from the richest segments to the rest of the distribution. In turn, parameter $p$ affects mostly the lower percentiles of the distribution. Specifically, an increase in this parameter implies that individuals with lower income receive a transfer of income from the rest of the percentiles, generating a decrease in inequality and poverty.

For a more in-depth interpretation of the parameters, Fig. 1 and 2 illustrate the impact of the Dagum model parameters on the Gini coefficient and the shares in total income of different quantiles (the contours in Fig. 1 show the value of the Gini coefficients

\footnotetext{
${ }^{4}$ Garcia and Prieto (2011) provide an exhaustive analysis of the influence of the parameters of the Dagum model on different measures of income distribution.
} 
at different combinations of Dagum distributions parameters $a$ and $p$ and those in Fig. 2 the combinations of the parameters that provide a specific income share). To assess this impact, values of the parameters that are suitable for developing countries have been chosen according to the estimates shown in Section 5. As can be seen in Fig. 1, the Gini coefficient is a decreasing function of both parameters $a$ and $p$. Moreover, when both parameters increase the income share of the poorest $25 \%$ of the population increases, while that of the richest part of the population decreases.

[Figure 1 here]

[Figure 2 here]

The next step in parametric modelling is to estimate the unknown parameters of the theoretical model. Given that available data for developing countries correspond to the empirical Lorenz curve ordinates and not to the complete income distributions (see more details in the next section), non-linear least squares parameters estimators are obtained minimising ${ }^{5}$ :

$$
\sum_{i=1}^{N}\left\{L_{n}\left(u_{i}\right)-B\left(u^{1 / p} ; p+1 / a, 1-1 / a\right)\right\}^{2}
$$

where $L_{n}($.$) is the empirical Lorenz curve, 0 \leq u \leq 1$ and $B\left(u^{1 / p} ; p+1 / a, 1-1 / a\right)$ is the value of cumulative distribution function of the Beta distribution with parameters $p+1 / a$ and $1-1 / a$ in the point $u^{1 / p}$ (that is, the Lorenz curve under the Dagum model).

The modelling process is completed with the analysis of the goodness-of-fit in order to confirm whether the model is suitable. For this purpose, a Kolmogorov-Smirnov statistic (defined in this case as the supremum between the empirical Lorenz curve and the

\footnotetext{
${ }^{5}$ See more details in Dagum (1977).
} 
Lorenz curve under the Dagum model) and the correlation coefficient between the sample Lorenz curve and the Lorenz curve estimated using the Dagum model will be used.

\section{Econometric models}

The second stage of the methodology is concerned with analysing econometrically the impact of particular macroeconomic variables on the parameters of the Dagum distribution that are directly related to inequality, $a$ and $p$. The econometrics analysis in this article applies the efficient method of estimating seemingly unrelated regressions (SUR) proposed by Zellner (1962). As will became clear later, one main advantage of this formulation is that it allows to introduce the variance-covariance matrix of $a \mathrm{y} p$ estimators obtained in the first stage 6 .

Let us assume that the performance of the Dagum parameter $a$ may be summarised in the following model:

$$
\mathbf{A}=X \beta^{a}+\varepsilon_{1} \quad E\left(\varepsilon_{1} \varepsilon_{1}^{\prime}\right)=\sigma_{11} I_{N}
$$

where $\mathbf{A}$ is the $N$-vector of the Dagum parameter $a$ for the $N$ countries, $X$ is the $N x k$ matrix of regressors including a constant term, $\beta^{a}$ is the $k$-vector of unknown parameters that describe the impact of the macroeconomic variables, $\varepsilon_{1}$ is the $N$-vector of i.i.d. normal error terms with zero mean, $\sigma_{11}$ is the variance of the error terms and $I_{N}$ is the $N \mathrm{x} N$ identity matrix.

Similarly, the equation of the Dagum parameter $p$ may be written as:

$$
\mathbf{P}=X \beta^{p}+\varepsilon_{2} \quad E\left(\varepsilon_{2} \varepsilon_{2}^{\prime}\right)=\sigma_{22} I_{N}
$$

\footnotetext{
${ }^{6}$ One alternative procedure would be to estimate two different equations, one for each parameter. Yet, this kind of formulation would allow introducing the variance of the parameter estimators, but not the covariance between them.
} 
where $\mathbf{P}$ is the $N$-vector of the Dagum parameter $p$ for the countries, $\beta^{p}$ is the $k$-vector of unknown parameters, $\varepsilon_{2}$ is the $N$-vector of i.i.d. normal error terms with zero mean and $\sigma_{22}$ is the variance of the error terms.

If $a$ and $p$ were observable, we could estimate the two equations separately applying, for example, OLS. However, this is not the case, although nonlinear least square estimators of $a$ and $p$ are available for each country, which are related to the unknown parameters of the Dagum model. This relationship can be expressed as $\hat{a}_{i}=a_{i}+\eta_{1 i}$ and $\hat{p}_{i}=p_{i}+\eta_{2 i}$, where $\eta_{1 i}$ and $\eta_{2 i}$ are two random perturbations. Let us assume that the distribution of these two perturbations is normal with zero mean and variance-covariance matrices determined by:

$$
E\left(\eta_{l i}, \eta_{m j}\right)=\sigma_{\eta_{l} \eta_{m}}^{i} \quad \text { if } i=j \text { and } 0 \text { in another case with } l, m=1,2 \text { and } i, j=1 \ldots N
$$

This means that we can acknowledge that $\eta_{1 i}$ and $\eta_{2 i}$ are correlated for the same country, although they are not related between different countries.

Thus, the two equations describing the behaviour of Dagum parameters could be expressed in function of the sample estimates of these parameters but its sampling variability should be introduced ${ }^{7}$. As Jäntti and Jenkins (2010) propose, we use a SUR system in order to incorporate the variances and covariances of the Dagum parameter estimators obtained in the first stage.

The SUR system can be written as:

$$
\hat{\theta}=Z \beta+\varepsilon+\eta
$$

\footnotetext{
${ }^{7}$ On the contrary, the models proposed by Thurow (1970) and Salem and Mount (1974) did not incorporate the sampling variability of the income distribution parameters estimators.
} 
where $\hat{\theta}$ is a $2 N$-vector consisting of $\hat{\mathbf{A}}$, the $N$-vector of the estimates of the Dagum parameter $a$, and $\hat{\mathbf{P}}$ the $N$-vector of the estimates of Dagum parameter $p$, staked vertically. The matrix $Z$ is a $2 N \times 2 k$ block-diagonal matrix. The diagonal blocks are $X$, the regressor matrix.

The vector is $\beta$ a $2 k$-vector consisting of the vectors $\beta^{a}$ and $\beta^{p}$ stacked vertically. Finally, $\varepsilon$ is the $2 N$-vector of error terms associated to two equations and $\eta$ is the $2 N$ vector of error terms associated to the Dagum parameters estimators.

The variance-covariance matrix of $\varepsilon$ would be expressed as:

$$
E\left(\varepsilon \varepsilon^{\prime}\right)=\Sigma \otimes I_{N}
$$

with $\Sigma$ being the $2 \times 2$ variance and covariance matrix of the perturbations of the two equations for a given country. The elements on the main diagonal are $\sigma_{11}$ and $\sigma_{22}$. The possibility that the error terms may be correlated across equations is considered assuming that the off-diagonal element, $\sigma_{12}$, is not equal to zero.

Assuming independence between $\varepsilon$ and $\eta$, the variance-covariance matrix of joint perturbations would be:

$$
\Gamma=\Sigma \otimes I_{N}+\Omega
$$

where

$$
\Omega=\left(\begin{array}{cccccccc}
\sigma_{\eta_{1} \eta_{1}}^{1} & 0 & \cdots & 0 & \sigma_{\eta_{1} \eta_{2}}^{1} & 0 & \cdots & 0 \\
0 & \sigma_{\eta_{1} \eta_{1}}^{2} & \cdots & 0 & 0 & \sigma_{\eta_{1} \eta_{2}}^{2} & \cdots & 0 \\
\vdots & \vdots & \vdots & \vdots & \vdots & \vdots & \vdots & \vdots \\
0 & 0 & \cdots & \sigma_{\eta_{1} \eta_{1}}^{N} & 0 & 0 & \cdots & \sigma_{\eta_{1} \eta_{2}}^{N} \\
\sigma_{\eta_{1} \eta_{2}}^{1} & 0 & \cdots & 0 & \sigma_{\eta_{2} \eta_{2}}^{1} & 0 & \cdots & 0 \\
0 & \sigma_{\eta_{1} \eta_{2}}^{2} & \cdots & 0 & 0 & \sigma_{\eta_{2} \eta_{2}}^{2} & \cdots & 0 \\
\vdots & \vdots & \vdots & \vdots & \vdots & \vdots & \vdots & \vdots \\
0 & 0 & \cdots & \sigma_{\eta_{1} \eta_{2}}^{N} & 0 & 0 & \cdots & \sigma_{\eta_{2} \eta_{2}}^{N}
\end{array}\right)
$$


It can be observed that the variances of the non-linear least square estimates for each period are found in the main diagonal of $\Omega$ (first those of parameter $a$ estimator and then those of parameter $p$ estimator). The elements outside the diagonal are the covariances between the estimators of the parameters which are assumed to be equal to zero (except for those corresponding to the estimators of the same country). Thus, taking into account the sampling variability of Dagum parameters estimates implies that the variances of perturbations of SUR model will be different across countries and equations. Besides, a source of correlation between the equations describing $a$ y $p$ is introduced, due to the correlation between the sample estimate parameters for each country.

The efficient estimator of $\beta$ would be given by the Generalised Least Squares Estimator (GLSE), if $\Gamma$ were known. As in our case it is unknown, through an iterative process, based on the estimation of $\Gamma$, the Feasible Generalised Least Squares Estimator (FGLSE) is obtained. If $\hat{\Gamma}$, the estimator of $\Gamma$, is consistent, then the FGLSE is an asymptotically efficient estimator. Based on the Zellner procedure (1962), a consistent estimator of $\Gamma$ would be obtained with a estimator of $\Sigma$ based on OLS residuals from the two equations and an estimator of $\Omega$ based on the variance-covariance matrices of the nonlinear least square estimator of the Dagum parameters for each country.

\section{Data}

The empirical analysis is conducted on a sample of developing countries for which two types of data are available: data on personal income distribution and macroeconomic indicators. The distributional data for these countries in terms of income distribution (or expenditure, depending on data availability) have been obtained from "PovcalNet", a database developed by World Bank (http://iresearch.worldbank.org/PovcalNet). PovcalNet 
contains data drawn from nationally representative household surveys, which are conducted by national statistical offices or by private agencies under the official supervision of government or international agencies. The per capita income/consumption measure used in this database is household income/consumption expenditure divided by the household size. The distributional information in the database consists of income/consumption shares by deciles based on Lorenz curves ${ }^{8}$.

The time period for the analysis, 2005, was selected as the most recent year with sufficient availability of countries with data regarding both income (or expenditure) distribution and the selected macroeconomic indicators. A final sample of 44 developing countries was obtained (a full list can be found in Table 1). Given the limited availability of homogeneous surveys in terms of time, it was not possible to use longitudinal information and, therefore, to examine the evolution of inequality along the business cycle (and the redistributive role of cycles), as well as the stability of the relationships. In 2005 the countries in the sample were facing in general a stage of significant economic growth in the year selected (only two of them exhibit negative growth rates) ${ }^{9}$, which must be considered in the interpretation of the results ${ }^{10}$.

The corresponding macroeconomic indicators have been extracted from the World Development Indicators database of the World Bank (http://data.worldbank.org/indicator). GDP growth rate is measured as the annual percentage growth rate of GDP at market prices based on constant local currency. Inflation is measured by the annual growth rate of

\footnotetext{
${ }^{8}$ The details of the survey of each country (including name, year, sampling size and geographical coverage) can be consulted in the data section of "PovcalNet" (http://iresearch.worldbank.org/PovcalNet).

${ }^{9} 2005$ was a year of widespread economic expansion (according to International Monetary Fund estimates, the growth of the world economy was of $4.8 \%$ and that of emerging and developing countries of $7.5 \%$ ).

${ }^{10}$ In order to evaluate the robustness of the results, we have estimated the models for two different subsamples of countries classified according to their growth rates. The hypotesis of equal coefficients could not be rejected. The results of the tests are avalailable from the authors on request.
} 
the GDP implicit deflator. In order to examine the influence of the labour market on income distribution, as information on unemployment rates is not available for all countries, the employment rate is used, defined as the proportion of the country's workingage population (usually individuals of 15 years and older are considered) that is employed. Finally, the interest rate indicator employed is the real interest rate, which is the lending interest rate adjusted for inflation as measured by the GDP deflator.

Table A.1 in the annex contains descriptive evidence regarding the macroeconomic variables and the income distribution of the sample of developing countries. With respect to the macroeconomic indicators, the inflation rate is relatively high (with an average of $10.3 \%$ ) and presents a high heterogeneity (the standard deviation is $6.05 \%$, with values ranging from deflation in countries like Uganda to values that exceed $20 \%$ in other countries). The average rate of employment slightly exceeds $59 \%$ of the working-age population and, again, exhibits a remarkable heterogeneity (with a standard deviation of $10.95 \%$ ). In turn, the GDP growth is also high and heterogeneous (with an average of $7.28 \%$, a standard deviation of $6.05 \%$ ) and the same is observed for the real interest rate for the group of countries in the sample (with an average of 8.65 and a standard deviation of $10.32 \%$ ). As regards the characteristics of income distribution, inequality is, on average, quite significant, although considerable differences are found across countries (the Gini index presents an average of 42.5 and a standard deviation of around 10).

\section{Results}

This section presents the results of the empirical examination of the effect of macroeconomic factors on inequality in developing countries. As previously mentioned, the first step in the analysis consists of the estimation through non-linear least squares of 
the parameters of the theoretical Dagum model separately for each country, departing from the income/consumption shares by deciles based on Lorenz curves. The estimation is limited to those parameters of the distribution, $a$ and $p$, that influence the Lorenz curve and, hence, inequality.

Table 1 shows the parameters estimated and their standard error and, in order to examine the results and the goodness-of-fit of the estimation of the parameters of the Dagum model, the standard error of the regression, the Kolmogorov-Smirnov statistic and the correlation coefficient between the empirical Lorenz curve and the estimated Lorenz curve based on the Dagum model. Overall, this evidence confirms that the Dagum model fits the data quite well. On the one hand, the values of the Kolmogorov-Smirnof statistic based on the Lorenz curve are systematically very low (ranging from 0.0005 in the case of Azerbaijan to 0.0081 in the case of Philippines). On the other hand, the correlation coefficient between the empirical Lorenz curve and the estimated Lorenz curve based on the Dagum model is, in general, very high (actually, in all cases it is very close to one). Finally, in a similar vein, the non-parametric estimation of the Gini index directly obtained by the World Bank for each country from the raw data is very similar to that inferred from the Dagum model after replacing the parameters by its estimates, with a correlation coefficient of both indices over 0.99. Consequently, the Dagum model accurately reproduces the income distribution in developing countries.

\section{[Table 1 here]}

The second step in the analysis consists of the estimation of the econometric model in order to examine the effect on income distribution of the macroeconomic factors (GDP growth rate, inflation rate, employment rate and the real interest rate). To this respect, 
Table 2 shows the results of the estimation of the seemingly unrelated regression equations system.

[Table 2 here]

In general, the regressors exhibit a significant joint explanatory power in both equations, although particularly in the equation related to the parameter $a$ of the Dagum distribution. In this last case, the $\tilde{F}$ statistic allows to reject the null hypothesis of zero significance for all the regressors in the equation at $5 \%$. In the case of the parameter $p$, the corresponding $\tilde{F}$ statistic is above the critical value of the $10 \%$ level of significance. With respect to the individual significance of the regressors, the results reveal that GDP growth rate and employment rate are significant variables in the determination of parameter $a$ and that real interest rate is a significant variable in the equation of parameter $p$. More specifically, the sign of the coefficients of these variables suggest that increases in both employment rate and real interest rate tend to increase inequality (given that parameters $a$ and $p$ decrease), whereas a higher GDP growth is associated with a lower inequality (considering its positive impact on parameter $a$ ). On the contrary, according to these findings, the inflation rate does not seem to have a significant impact on inequality ${ }^{11}$.

Additionally, the distributive effects of the macroeconomic variables can be examined in detail taking advantage of the fact that different distributional statistics, comprising inequality indices and the income shares of the different quantiles of the income distribution, can be expressed as functions of the estimated parameters of the Dagum model which, in turn, are a function of the macroeconomic variables, determined

\footnotetext{
${ }^{11}$ These results are very similar to OLS estimations (detailed results are available from authors on request). Note that GLS and OLS estimators would coincide if the sample variability of the Dagum parameter estimates were not introduced in the SUR system. Under our assumptions, the OLS estimator is consistent and the FGLS estimator also, provided that the variance-covariance matrix of the joint errors has been estimated correctly.
} 
by the estimation of the SUR model. This permits to express each of these distributional statistics as a function of parameters estimates of the Dagum model and to analyse the influence of the macroeconomic factors on income distribution according to its influence in the distributional statistics. As a final stage of the empirical analysis, this approach has been applied to the Gini coefficient and the income shares of the four quartiles of the distribution. $^{12}$

Fig. 3 shows the variations in the Gini index in response to changes in GDP growth, inflation, employment and interest rates in the range of values of these variables for the countries in the sample. When the impact of one macroeconomic variable is examined, the values of the remaining variables are evaluated in their respective averages in order to provide the corresponding profile. Similarly, Fig. 4 contains similar functions regarding the influence of the set of macroeconomic factors on the income share of the four quartiles of the income distribution.

[Figure 3 here]

[Figure 4 here]

Beginning with the analysis of the impact of the GDP growth rate, the evidence confirms that an increase in the growth rate significantly reduces the level of inequality measured through the Gini index and that GDP growth is the variable with the greatest influence on the level of inequality. Accordingly, an increase in the growth rate generates increases in the shares of total income of the first three quartiles of the distribution and a

\footnotetext{
${ }^{12}$ For example, in the case of the relationship between the Gini index and employment, knowing that the Gini index is a function of the parameters $a$ and $p G=\frac{\Gamma(p) \Gamma(2 p+1 / a)}{\Gamma(2 p) \Gamma(p+1 / a)}-1$, and as $a$ and $p$ are unknown, we will substitute them with the FGLS estimation of the SUR model. By substituting the values of the employment rate in the expression of the Gini index and maintaining the rest of the variables constant, we can examine how the variations in the employment rate affect the Gini index.
} 
decrease in the share of the richest $25 \%$ of the population. Moreover, these variations are apparently more significant when developing countries have low growth rates, suggesting the presence of a non-linear effect of this variable.

As regards the influence of the inflation rate on income distribution, it can be observed that an increase in the rate of inflation causes very little variation in the Gini index. The low influence of this variable on inequality coincides with the results in Table 2 , given that the inflation rate is not a significant variable when explaining none of the Dagum parameters. Consequently, the shares of the total income of the different quartiles hardly fluctuate when the level of inflation varies.

According to this evidence, an increase in the rate of employment is associated with a slight increase in the levels of inequality in developing countries. This result is consistent with the fact that whereas the income share of the fourth quartile tends to increase when the employment rate increases, those of the first and second quartiles remain almost constant and the income share of the third quartile diminishes.

Finally, the evidence confirms that, as suggested by the negative sign of the coefficient of the real interest rate on the equations describing the Dagum parameters (Table 2), real interest rates have a significant positive impact on inequality. Therefore, when real interest rates rise, inequality increases and, accordingly, the income share of the most disadvantaged quartiles diminishes and that of the richest quartile increases. Moreover, the impact seems more severe at higher interest rate levels.

\section{Conclusions}

The aim of this article is to examine the effect of macroeconomic factors on personal income distribution in developing countries, a field where previous evidence is 
scarce and inconclusive. The empirical analysis is based on the estimation of parameters of a theoretical model, which provides a good fit to empirical income distributions and their subsequent use, as dependent variables, in econometric models that include macroeconomic variables such as inflation, employment rate, growth and real interest rates as regressors. This approach provides a more accurate perspective than that obtained through the standard use of a specific inequality index, as is usual in previous related studies.

The results of the first stage of the empirical analysis show that the theoretical parametric Dagum model provides an excellent fit to the empirical income distribution of developing countries and that the parameter estimations are fairly precise for each country. The second stage of the analysis confirms that the macroeconomic variables included in the model are jointly significant in the explanation of the parameters of the model and that GDP growth, employment rate and real interest rate are the variables with the greatest impact on the Dagum parameters which affect inequality. At this point, it is important to note that this finding contrasts with the empirical evidence of previous studies regarding the lack of a systematic relationship between growth and inequality. On the contrary, according to the obtained empirical evidence, inflation rate is not a significant variable when explaining Dagum inequality parameters in developing countries. This finding is consistent with the mixed evidence of previous studies on the effect of inflation on inequality.

The subsequent use of the econometric estimations with the aim to evaluate the impact of the macroeconomic factors in different distributional statistics of the distribution (the Gini index and the income shares of the four quartiles of the distribution) confirm that growth and real interest rates are factors with a significant distributive influence. More 
specifically, higher growth rates are associated with a decrease in the Gini index and an increase in the shares of total income of the most disadvantaged population segments. On the contrary, increases in real interest rates give rise to an increase in inequality in developing countries.

Overall, the results obtained suggest that pro-growth structural reforms as well as policies aimed at decreasing real interest rates can lead to decreasing income disparities in the context of developing countries in a period of economic growth. Consequently, policymakers in developing countries can find possible trade-offs between simultaneous strategies that pursue efficiency and equality and the benefits of economic growth can favour the disadvantaged. On the contrary, policies to control the inflation have not a clear effect on the inequality in developing countries and can have opposite effects depending on the specific characteristics of each economy. 


\section{References}

Aghion, P. and Bolton, P. (1997) A trickle-down theory of economic growth and development, Review of Economic Studies, 64, 151-72.

Al-Marhubi, F. A. (2000) Income Inequality and Inflation: The cross-country evidence, Contemporary Economic Policy, 18, 428-439.

Blank, R. and Blinder, A.S. (1986) Macroeconomics, Income Distribution, and Poverty, in Fighting Poverty: What Works and What Doesn't (Eds.) H. Sheldon, Danzinger and D. H. Weinberg, Cambridge, Harvard University Press, pp.180-208.

Blinder, A. and Esaki, H. (1978) Macroeconomic Activity and Income Distribution in the Postwar United States, Review of Economics and Statistics, 60 (4), 604-609.

Bourguignon, F (2003) The Growth Elasticity of Poverty Reduction: Explaining Heterogeneity across Countries and Time Periods, in Inequality and growth. Theory and Policy Implications (Eds.) T. Eicher and S. Turnovsky, Cambridge: The MIT Press.

Bulìr, A. (2001) Income Inequality: Does Inflation matter? International Monetary Fund Staff Papers. Vol. 48, No.1.

Castañeda, A., Díaz-Giménez, J. and Ríos-Rull, J.V. (1998) Exploring the Income Distribution Business Cycle Dynamics, Journal of Monetary Economics, 42, 93-130.

Chen, S. and Ravallion, M. (2010) The Developing World is Poorer Than We Thought, But no Less Successful in the Fight Against Poverty, The Quarterly Journal of Economics, 125, 1577-1622.

Cutler, D. M., and Katz, L.F. (1991) Macroeconomic Performance and the Disadvantaged, Brookings Papers on Economic Activity, 2, 1-74.

Dagum, C. (1977) A new model of personal expenditure distribution: Specification and estimation, Economie Appliquée, 30, 413-437.

Deininger, K. and Squire, L. (1996) A New Data Set Measuring Income Inequality, World Bank Economic Review 10, 565-91.

Fields, G. (1989) Changes in Poverty and Inequality in Developing Countries, World Bank Research Observer, 4, 167-186.

García, C. and Prieto, M. (2011) Using the Dagum Model to Explain Changes in Personal Income Distribution, Applied Economics, 43, 4377-4386.

Jäntti, M. and Jenkins, S.P. (2010) Examining the Impact of Macroeconomic Conditions on Income Inequality, Journal of Economic Inequality, 8, 221-240.

Kleiber, C. (1996) Dagum vs. Singh-Maddala expenditure distributions, Economics Letters, 53, 265-268.

Kuznets, S. (1955) Economic Growth and Income Inequality, American Economic Review, 45, $1-28$.

McDonald, J. B. (1984) Some generalized functions for the size distribution of expenditure, Econometrica, 52, 647-663.

McDonald, J. B. and Xu, Y.J. (1995) A generalization for the beta distribution with applications, Journal of Econometrics, 66, 133-152.

Milanovic, B. (2005) Can We Discern the Effect of Globalization on Income Distribution? Evidence from Household Surveys, World Bank Economic Review, 19, 21-44.

Parker, S.C. (1999) Income inequality and the business cycle: survey of the evidence and some new results, Journal of Post Keynesian Economics, 21, 201-225.

Piketty, T. (1997) The dynamics of the wealth distribution and the interest rate with credit rationing, Review of Economic Studies, 64, 173-201. 
Ravallion, M. (2003) Measuring Aggregate Welfare in Developing Countries: How Well do National Accounts and Surveys Agree? Review of Economics and Statistics, 85, 645-652.

Salem, S.K. and Mount G. S. (1974) A convenient descriptive model of income distribution: the Gamma distribution, Econometrica, 42, 115-127.

Thornton, J. (2001) The Kuznets Inverted-U Hypothesis: Panel Data Evidence from 96 countries, Applied Economics Letters, 8, 15-26.

Thurow, L.C. (1970) Analyzing the American Income Distribution, American Economic Review, 60, 261-269.

Victoria-Feser, M.P. (1995) Robust methods for personal income distribution models with applications to Dagum's models, in Research on Economic Inequality (1) (Eds.) C. Dagum and A. Lemmi, Greenwich, CT, JAI Press, pp. 123-157.

Victoria-Feser, M.P. (2000) Robust methods for the analysis of income distribution, inequality and poverty, International Statistical Review, 68, 277-293.

Zellner, A. (1962) An Efficient Method of Estimating Seemingly Unrelated Regressions Bias, Journal of the American Statistical Association, 57, 346-68. 
Tables and figures

Table 1. Estimations of the parameters of the Dagum model and goodness-of-fit statistics.

\begin{tabular}{|c|c|c|c|c|c|}
\hline & Parameter $a$ & Parameter $p$ & $\begin{array}{l}\text { Standard } \\
\text { error }\end{array}$ & $\begin{array}{l}\text { Kolmogorov- } \\
\text { Smirnof } \\
\text { statistic }\end{array}$ & $\begin{array}{c}\text { Coefficient of } \\
\text { correlation of } \\
\text { actual and } \\
\text { predicted Lorenz } \\
\text { curves }\end{array}$ \\
\hline Albania & $\begin{array}{l}3.0583 \\
(0.0415)\end{array}$ & \begin{tabular}{|l}
0.9372 \\
$(0.0555)$
\end{tabular} & 0.0023 & 0.0035 & 0.99996 \\
\hline Azerbaijan & $\begin{array}{l}5.0404 \\
(0.0188)\end{array}$ & $\begin{array}{l}2.3399 \\
(0.0708)\end{array}$ & 0.0003 & 0.0005 & 1.00000 \\
\hline Belarus & $\begin{array}{l}3.8959 \\
(0.0640)\end{array}$ & $\begin{array}{l}0.7251 \\
(0.0375)\end{array}$ & 0.0021 & 0.0028 & 0.99997 \\
\hline Bhutan & $\begin{array}{l}2.0187 \\
(0.0208)\end{array}$ & $\begin{array}{l}1.4299 \\
(0.1290)\end{array}$ & 0.0030 & 0.0043 & 0.99992 \\
\hline Bolivia & $\begin{array}{l}2.0166 \\
(0.0040)\end{array}$ & $\begin{array}{l}0.4455 \\
(0.0033)\end{array}$ & 0.0005 & 0.0007 & 1.00000 \\
\hline Bosnia-Herzegovina & $\begin{array}{l}2.9205 \\
(0.0373)\end{array}$ & $\begin{array}{l}0.8129 \\
(0.0417)\end{array}$ & 0.0023 & 0.0034 & 0.99996 \\
\hline Brazil & $\begin{array}{l}1.8716 \\
(0.0104)\end{array}$ & $\begin{array}{l}0.7171 \\
(0.0221)\end{array}$ & 0.0017 & 0.0028 & 0.99997 \\
\hline Bulgaria & $\begin{array}{l}3.4138 \\
(0.0123)\end{array}$ & $\begin{array}{l}1.0193 \\
(0.0161)\end{array}$ & 0.0005 & 0.0011 & 1.00000 \\
\hline Central African Republic & $\begin{array}{l}2.3988 \\
(0.0399)\end{array}$ & $\begin{array}{l}0.7732 \\
(0.0577)\end{array}$ & 0.0037 & 0.0052 & 0.99989 \\
\hline Chad & $\begin{array}{l}2.5090 \\
(0.0339)\end{array}$ & $\begin{array}{l}0.9752 \\
(0.0681)\end{array}$ & 0.0029 & 0.0043 & 0.99994 \\
\hline Colombia & $\begin{array}{l}1.8578 \\
(0.0072)\end{array}$ & $\begin{array}{l}0.6104 \\
(0.0118)\end{array}$ & 0.0012 & 0.0019 & 0.99999 \\
\hline Comoros & $\begin{array}{l}1.4932 \\
(0.0042)\end{array}$ & $\begin{array}{l}1.6624 \\
(0.0748)\end{array}$ & 0.0012 & 0.0018 & 0.99997 \\
\hline Congo, Dem. Rep. & $\begin{array}{l}2.2169 \\
(0.0299)\end{array}$ & $\begin{array}{l}1.0488 \\
(0.0864)\end{array}$ & 0.0034 & 0.0047 & 0.99990 \\
\hline Congo, Rep. & $\begin{array}{l}2.0899 \\
(0.0313)\end{array}$ & $\begin{array}{l}1.0184 \\
(0.0967)\end{array}$ & 0.0041 & 0.0054 & 0.99985 \\
\hline Dominican Republic & $\begin{array}{l}2.0848 \\
(0.0166)\end{array}$ & $\begin{array}{l}0.7898 \\
(0.0327)\end{array}$ & 0.0021 & 0.0034 & 0.99996 \\
\hline Ecuador & $\begin{array}{l}1.9484 \\
(0.0070)\end{array}$ & $\begin{array}{l}0.7730 \\
(0.0154)\end{array}$ & 0.0010 & & 0.99999 \\
\hline Ethiopia & $\begin{array}{l}2.9295 \\
(0.0278)\end{array}$ & $\begin{array}{l}2.4798 \\
(0.2536)\end{array}$ & 0.0017 & 0.0031 & 0.99998 \\
\hline Gambia, The & $\begin{array}{l}2.1164 \\
(0.0231)\end{array}$ & $\begin{array}{l}0.9642 \\
(0.0629)\end{array}$ & 0.0029 & 0.0042 & 0.99992 \\
\hline Georgia & $\begin{array}{l}2.6779 \\
(0.0173)\end{array}$ & $\begin{array}{l}0.6771 \\
(0.0163)\end{array}$ & 0.0013 & 0.0018 & 0.99999 \\
\hline Guatemala & $\begin{array}{l}1.9126 \\
(0.0081)\end{array}$ & $\begin{array}{l}0.8518 \\
(0.0221)\end{array}$ & 0.0013 & 0.0021 & 0.99998 \\
\hline Honduras & $\begin{array}{l}1.9797 \\
(0.0059)\end{array}$ & $\begin{array}{l}0.5385 \\
(0.0068)\end{array}$ & 0.0008 & 0.0012 & 0.99999 \\
\hline Iran, Islamic Rep. & $\begin{array}{l}2.6645 \\
(0.0252)\end{array}$ & $\begin{array}{l}0.8951 \\
(0.0390)\end{array}$ & 0.0019 & 0.0029 & 0.99997 \\
\hline Jamaica & $\begin{array}{l}2.1855 \\
(0.0196)\end{array}$ & $\begin{array}{l}1.0188 \\
(0.0552)\end{array}$ & 0.0023 & 0.0038 & 0.99996 \\
\hline Jordan & $\begin{array}{l}2.4270 \\
(0.0089)\end{array}$ & $\begin{array}{l}1.7648 \\
(0.0578)\end{array}$ & 0.0008 & 0.0013 & 0.99999 \\
\hline Kenya & $\begin{array}{l}2.0679 \\
(0.0067)\end{array}$ & $\begin{array}{l}1.1041 \\
(0.0246)\end{array}$ & 0.0009 & 0.0014 & 0.99999 \\
\hline Kyrgyz Republic & $\begin{array}{l}2.9461 \\
(0.0651)\end{array}$ & $\begin{array}{l}1.1017 \\
(0.1242)\end{array}$ & 0.0039 & 0.0059 & 0.99989 \\
\hline
\end{tabular}




\begin{tabular}{|c|c|c|c|c|c|}
\hline Liberia & $\begin{array}{l}2.5916 \\
(0.0159)\end{array}$ & $\begin{array}{l}1.0841 \\
(0.0366)\end{array}$ & 0.0013 & 0.0023 & 0.99999 \\
\hline Macedonia, FYR & $\begin{array}{l}2.7168 \\
(0.0345)\end{array}$ & $\begin{array}{l}0.7623 \\
(0.0389)\end{array}$ & 0.0024 & 0.0036 & 0.99996 \\
\hline Malawi & $\begin{array}{l}2.3432 \\
(0.0097)\end{array}$ & $\begin{array}{l}1.8262 \\
(0.0714)\end{array}$ & 0.0010 & 0.0016 & 0.99999 \\
\hline Moldova, Rep. & $\begin{array}{l}2.7407 \\
(0.0191)\end{array}$ & $\begin{array}{l}1.1224 \\
(0.0425)\end{array}$ & 0.0013 & 0.0021 & 0.99999 \\
\hline Mongolia & $\begin{array}{l}3.4293 \\
(0.0681)\end{array}$ & $\begin{array}{l}0.6213 \\
(0.0371)\end{array}$ & 0.0029 & 0.0039 & 0.99995 \\
\hline Nicaragua & $\begin{array}{l}1.9057 \\
(0.0049)\end{array}$ & $\begin{array}{l}1.0316 \\
(0.0189)\end{array}$ & 0.0008 & 0.0011 & 0.99999 \\
\hline Nigeria & $\begin{array}{l}2.4762 \\
(0.0292)\end{array}$ & $\begin{array}{l}0.7299 \\
(0.0360)\end{array}$ & 0.0025 & 0.0037 & 0.99995 \\
\hline Pakistan & $\begin{array}{l}2.7812 \\
(0.0116)\end{array}$ & $\begin{array}{l}2.7251 \\
(0.1390)\end{array}$ & 0.0008 & 0.0014 & 1.00000 \\
\hline Paraguay & $\begin{array}{l}1.9878 \\
(0.0061)\end{array}$ & $\begin{array}{l}0.6792 \\
(0.0103)\end{array}$ & 0.0009 & 0.0013 & 0.99999 \\
\hline Peru & $\begin{array}{l}1.9875 \\
(0.0121)\end{array}$ & $\begin{array}{l}0.8169 \\
(0.0281)\end{array}$ & 0.0017 & 0.0028 & 0.99997 \\
\hline Philippines & $\begin{array}{l}2.2638 \\
(0.0521)\end{array}$ & $\begin{array}{l}0.9532 \\
(0.1217)\end{array}$ & 0.0056 & 0.0081 & 0.99973 \\
\hline Sierra Leone & $\begin{array}{l}2.2445 \\
(0.0316)\end{array}$ & $\begin{array}{l}1.2716 \\
(0.1274)\end{array}$ & 0.0035 & 0.0049 & 0.99989 \\
\hline Tajikistan & $\begin{array}{l}2.9688 \\
(0.0366)\end{array}$ & $\begin{array}{l}0.9945 \\
(0.0571)\end{array}$ & 0.0021 & 0.0033 & 0.99997 \\
\hline Uganda & $\begin{array}{l}2.2092 \\
(0.0175)\end{array}$ & $\begin{array}{l}1.4409 \\
(0.0919)\end{array}$ & 0.0020 & 0.0035 & 0.99997 \\
\hline Ukraine & $\begin{array}{l}3.6738 \\
(0.0635)\end{array}$ & $\begin{array}{l}0.8519 \\
(0.0539)\end{array}$ & 0.0023 & 0.0034 & 0.99997 \\
\hline Vietnam & $\begin{array}{l}2.3181 \\
(0.0283)\end{array}$ & $\begin{array}{l}1.8405 \\
(0.2162)\end{array}$ & 0.0029 & 0.0043 & 0.99993 \\
\hline Yemen, Rep. & $\begin{array}{l}2.4183 \\
(0.0116)\end{array}$ & $\begin{array}{l}1.8866 \\
(0.0856)\end{array}$ & 0.0011 & 0.0021 & 0.99999 \\
\hline Zambia & $\begin{array}{l}2.1051 \\
(0.0173)\end{array}$ & $\begin{array}{l}0.6876 \\
(0.0264)\end{array}$ & 0.0021 & 0.0030 & 0.99996 \\
\hline
\end{tabular}


Table 2. Estimation of the seemingly unrelated regression equations system (SUR).

\begin{tabular}{lll}
\hline \multirow{2}{*}{ Regressors } & \multicolumn{2}{l}{ Parameters of the Dagum model } \\
& $A$ & $P$ \\
\hline Intercept & 3.187 & 0.752 \\
& $(0.469)$ & $(0.418)$ \\
GDP growth rate & $0.036^{* *}$ & 0.016 \\
& $(0.014)$ & $(0.012)$ \\
Inflation rate & 0.013 & -0.010 \\
& $(0.012)$ & $(0.011)$ \\
Employment rate & $-0.017^{* *}$ & 0.008 \\
& $(0.008)$ & $(0.007)$ \\
Real interest rate & -0.010 & $-0.018^{* *}$ \\
$\tilde{F}$ value & $(0.009)$ & $(0.008)$ \\
Significance of all the regressors in each equation & $4.991 * *$ & $2.070^{*}$ \\
$\tilde{F}$ value & & \\
Significance of all the regressors in both equations & $3.3892^{* *}$ & \\
& & \\
\hline
\end{tabular}

Note: A double asterisk indicates significance at the 5\% level and a single asterisk indicates significance at the $10 \%$ level. Standard errors in brackets. 


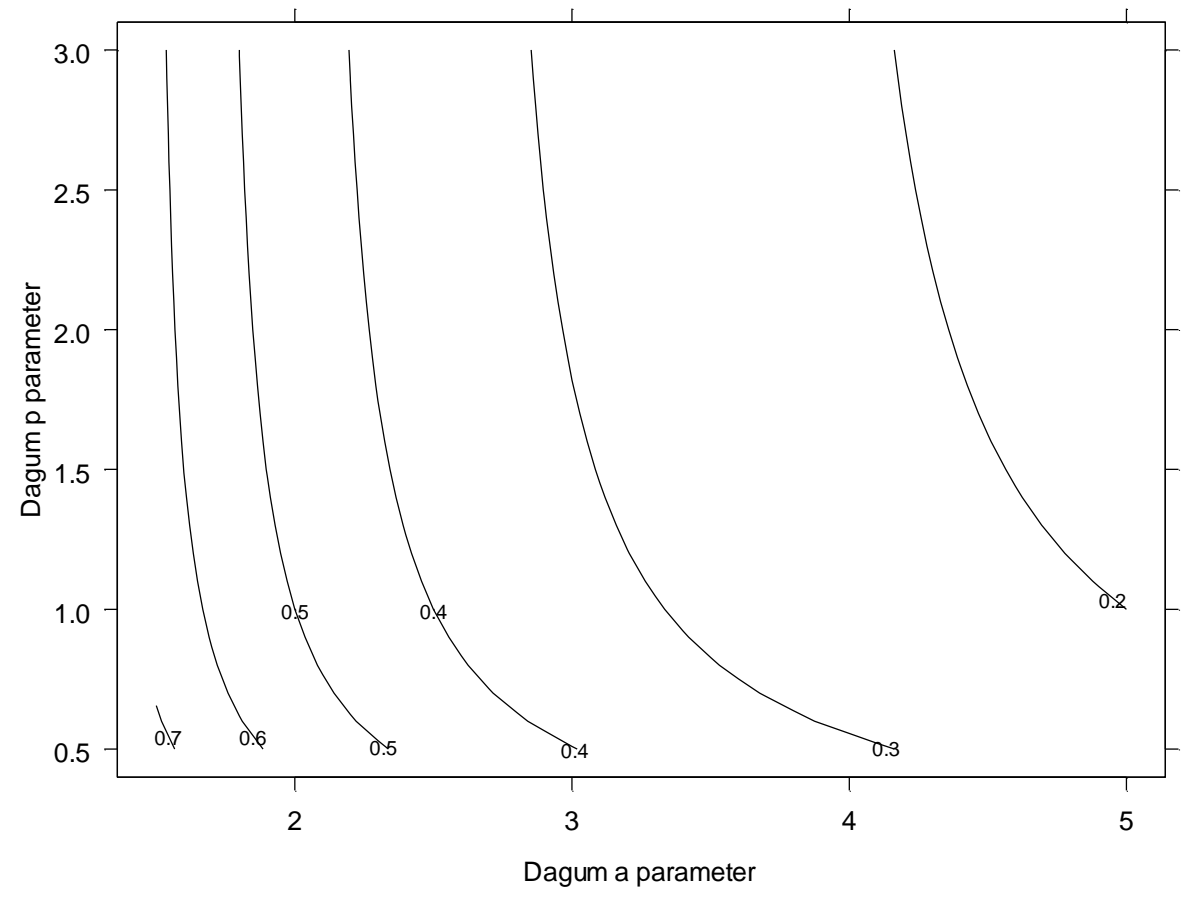

Figure 1. Gini coefficient as a function of the Dagum model parameters. 

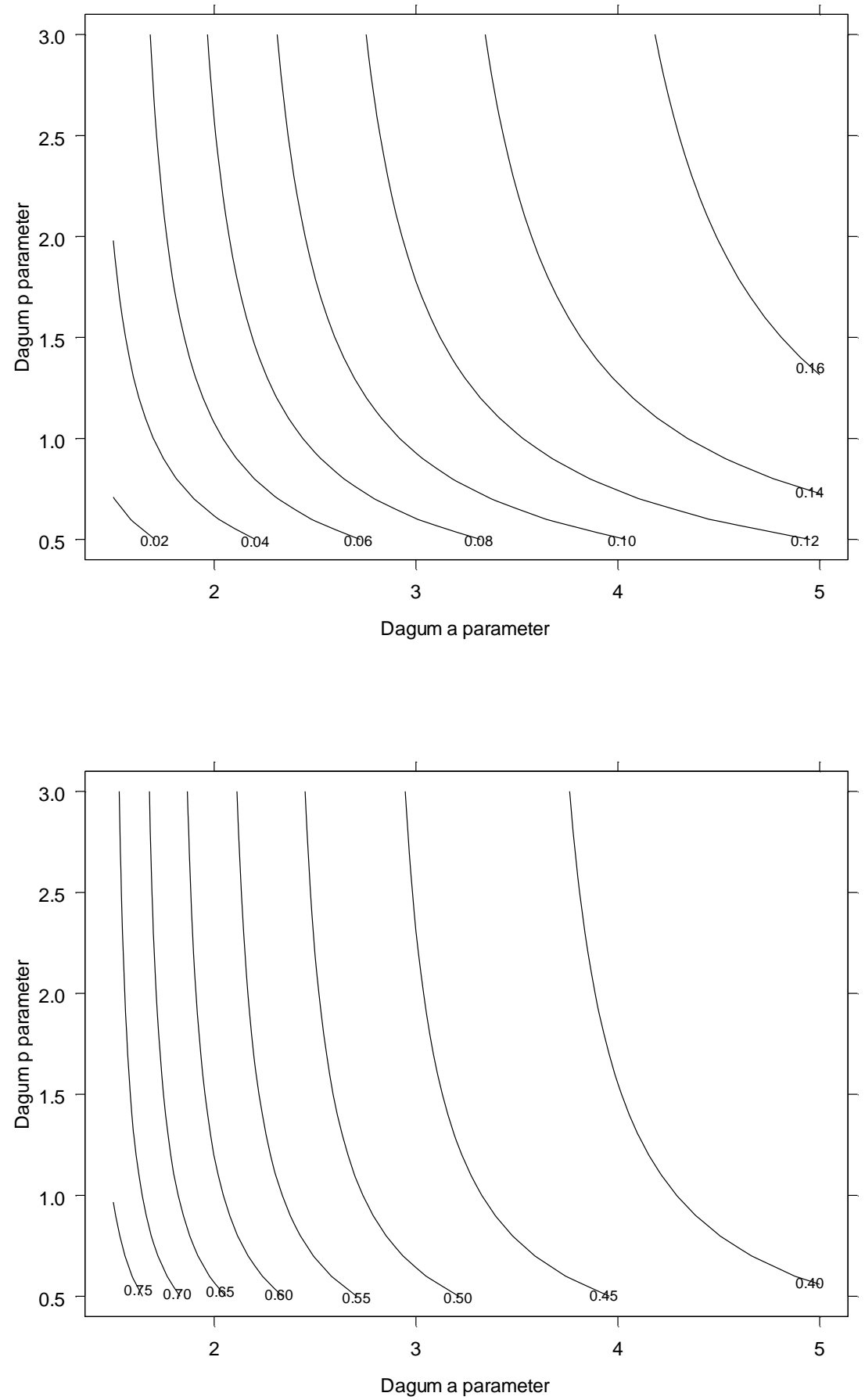

Figure 2. Quartile group income shares as a function of Dagum distribution function parameters. Income share held by the lowest and richest $25 \%$ of the population (upper and lower panel). 

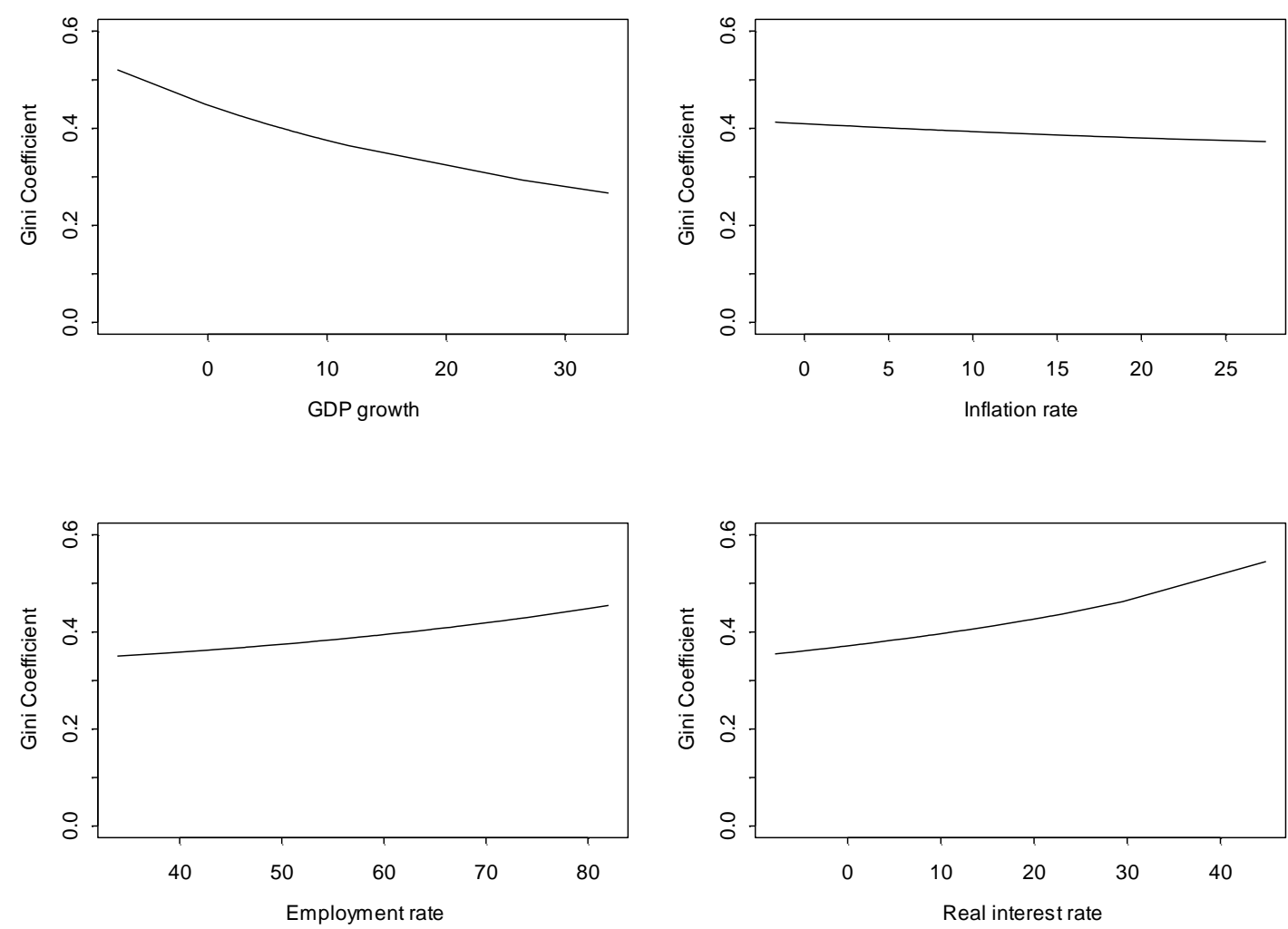

Figure 3. Impact of macroeconomic variables on the Gini coefficient. 

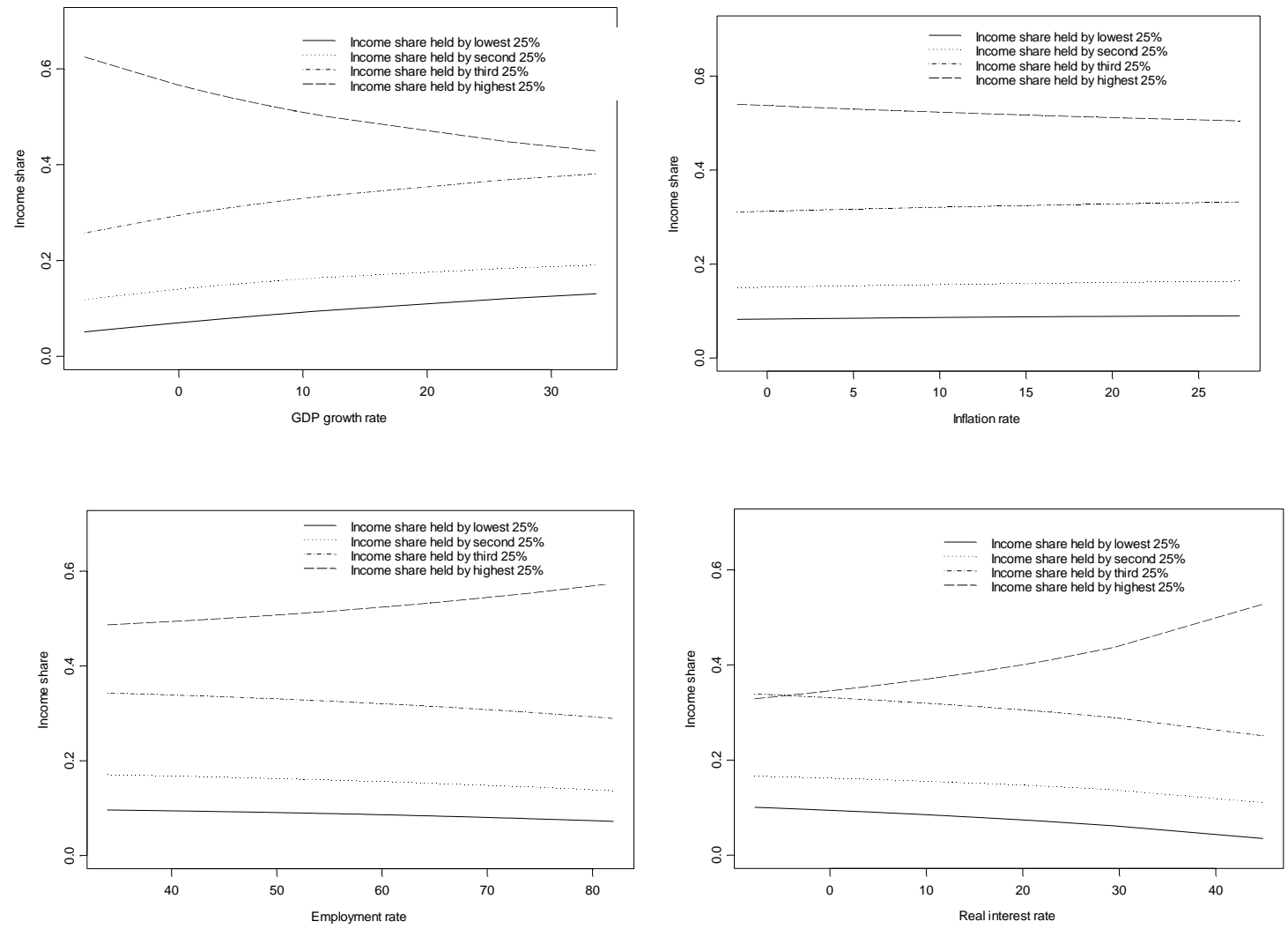

Figure 4. Impact of macroeconomic variables on the income share held by the quartiles of the income distribution. 
Annex

Table A.1. Descriptives.

\begin{tabular}{|c|c|c|c|c|c|}
\hline & GDP growth & Inflation & $\begin{array}{l}\text { Employment } \\
\text { ratio }\end{array}$ & $\begin{array}{l}\text { Real interest } \\
\text { rate }\end{array}$ & Gini index \\
\hline Albania & 5.50 & 3.47 & 46.40 & 9.30 & 33.03 \\
\hline Azerbaijan & 26.40 & 16.14 & 58.80 & 0.80 & 16.83 \\
\hline Belarus & 9.44 & 20.72 & 53.30 & -7.80 & 27.92 \\
\hline Bhutan & 8.97 & 6.30 & 57.50 & 8.20 & 46.83 \\
\hline Bolivia & 9.43 & 5.94 & 67.50 & 10.10 & 58.19 \\
\hline Bosnia-Herzegovina & 6.10 & 2.57 & 43.40 & 7.50 & 35.78 \\
\hline Brazil & 3.16 & 7.21 & 63.90 & 44.90 & 56.39 \\
\hline Bulgaria & 5.01 & 2.27 & 43.40 & 6.10 & 29.24 \\
\hline Central African Republic & -7.60 & -1.33 & 73.00 & 19.60 & 43.57 \\
\hline Chad & 33.63 & 9.73 & 66.50 & 7.50 & 39.78 \\
\hline Colombia & 6.94 & 5.78 & 51.20 & 6.70 & 58.49 \\
\hline Comoros & -0.24 & 1.77 & 72.70 & 9.10 & 64.30 \\
\hline Congo, Dem. Rep. & 6.46 & 21.56 & 65.40 & 29.50 & 44.43 \\
\hline Congo, Rep. & 7.70 & 21.28 & 67.50 & -3.00 & 47.32 \\
\hline Dominican Republic & 9.26 & 2.69 & 53.40 & 20.90 & 49.97 \\
\hline Ecuador & 6.00 & 7.47 & 57.30 & 2.00 & 53.65 \\
\hline Ethiopia & 11.82 & 9.88 & 80.10 & -2.60 & 29.76 \\
\hline Gambia, The & 6.87 & 27.39 & 73.10 & 1.50 & 47.28 \\
\hline Georgia & 9.60 & 7.93 & 54.90 & 12.70 & 40.78 \\
\hline Guatemala & 5.38 & 4.99 & 64.70 & 7.40 & 53.69 \\
\hline Honduras & 6.05 & 7.28 & 59.30 & 10.80 & 56.71 \\
\hline Iran, Islamic Rep. & 4.62 & 17.01 & 46.50 & -0.90 & 38.28 \\
\hline Jamaica & 1.39 & 12.72 & 58.10 & 4.80 & 45.51 \\
\hline Jordan & 8.03 & 15.14 & 42.80 & -6.00 & 37.72 \\
\hline Kenya & 5.91 & 4.90 & 74.00 & 7.60 & 47.68 \\
\hline Kyrgyz Republic & 7.03 & 5.11 & 58.10 & 23.00 & 32.93 \\
\hline Liberia & 9.40 & 15.96 & 67.20 & -0.79 & 38.16 \\
\hline Macedonia, FYR & 2.82 & 0.26 & 33.90 & 15.70 & 38.95 \\
\hline Malawi & 5.68 & 14.70 & 71.60 & 19.30 & 39.02 \\
\hline Moldova, Rep. & 7.41 & 7.98 & 47.30 & 12.00 & 35.60 \\
\hline Mongolia & 7.25 & 20.10 & 62.50 & 8.70 & 33.03 \\
\hline Nicaragua & 4.35 & 9.87 & 58.40 & 2.00 & 52.33 \\
\hline Nigeria & 10.60 & 20.73 & 52.60 & 8.60 & 42.93 \\
\hline Pakistan & 7.37 & 7.75 & 48.10 & -0.50 & 31.18 \\
\hline Paraguay & 2.88 & 8.08 & 66.20 & 20.20 & 53.89 \\
\hline Peru & 6.83 & 2.96 & 62.20 & 21.90 & 51.97 \\
\hline Philippines & 5.34 & 4.95 & 59.10 & 4.60 & 44.04 \\
\hline Sierra Leone & 9.29 & 8.40 & 64.60 & 10.70 & 42.52 \\
\hline Tajikistan & 10.60 & 17.20 & 55.20 & 2.70 & 33.61 \\
\hline Uganda & 6.33 & -1.74 & 82.00 & 21.80 & 42.62 \\
\hline Ukraine & 2.70 & 24.55 & 53.60 & -6.70 & 28.21 \\
\hline Vietnam & 7.79 & 8.18 & 71.10 & 1.40 & 39.16 \\
\hline Yemen, Rep. & 5.59 & 18.41 & 38.60 & -0.40 & 37.69 \\
\hline Zambia & 5.44 & 19.14 & 60.60 & 9.70 & 50.74 \\
\hline Average & 7.28 & 10.30 & 59.26 & 8.65 & 42.54 \\
\hline Median & 6.65 & 8.03 & 58.95 & 7.55 & 42.57 \\
\hline Standard deviation & 6.05 & 7.42 & 10.95 & 10.32 & 9.98 \\
\hline
\end{tabular}


